\title{
SOX11 Transcription Factor Staining Method
}

National Cancer Institute

\section{Source}

National Cancer Institute. SOX11 Transcription Factor Staining Method. NCI Thesaurus.

Code C138121.

Any of various immunohistochemical procedures for visualizing and/or quantitating SOX11 transcription factor expression in a sample. Dysregulation of SOX11 is associated with several types of cancer and has diagnostic and prognostic value. 